\title{
Empirical Research Concerning the Elimination of Violence in Mathematics Lessons
}

\author{
Costica $\operatorname{Lupu}_{1}$
}

\section{ABATRACT}

Due to the maladjustment of the teaching-learning style and strategies to the school activity, there occur numerous short- and long-term consequences. Students lose their self-esteem, become introverts, depressive, with complexes and fearful of their mates or teachers, eventually losing their ability to function well in society.

This study presents an empirical research on the identification and observation of the students' manifestations in various violent situations, among which: the feeling of injustice, lack of empathy, the devaluation of the student, emotional immaturity, the parents' or teachers' impulsiveness, lack of self-control, the environment and social circumstances, the teachers' or parents' disrespect.

The questionnaire and test we applied have shown the high relevance of being aware of the harmful effects of violence, the need for proper behaviour and appropriate teaching-learning style, the need to raise awareness, through social campaigns and educational programmes aimed at building a culture of non-violence, as well as diminishing the manifestation of violence in human relations.

Regarding these issues, we are searching for answers and the best teaching-learning strategies used to enhance enthusiasm for school activities, diminish the number of school absences, eliminate consumption of alcohol, tobacco, coffee or drugs, which may lead to increased violence in schools.

Keywords: aggression, violence, educational style, behaviour, cooperation

\section{INTRODUCTION:}

This study supports in understanding and preventing the difficulties of students in school life through methods, which may assist the student in reaching high levels of performance without much difficulty. Since any new situation is perceived as a stressful agent, these should be placed within a less official context, in order to accustom the student to the respective situation. The diversity of new situations is even more necessary as it may assist students in training for professional life.

\footnotetext{
1“Vasile Alecsandri" University of Bacau, Department of Mathematics-Informatics and Sciences of Education, Calea Mărășești, No 157, 600115, Bacău, Romania

(C) 2015, C Lupu; licensee IJIP. This is an Open Access Research distributed under the terms of the Creative Commons Attribution License (http://creativecommons.org/licenses/by/2.0), which permits unrestricted use, distribution, and reproduction in any Medium, provided the original work is properly cited.
} 
That is why we believe that a pleasant work environment in initial situations may help the group in adapting to stressful situations and reach higher efficiency rates for their work.

In order to investigate, analyse and describe a wide range of perspectives, the research team comprising a sample of 20 students from the Faculty of Mathematics, attending their initial teacher training study programme, will apply an initial and final test to evaluate the aggression potential, as well as a questionnaire on the inappropriate behaviour of some teachers.

\section{Theoretical background}

\section{I.1. Conceptual outlines}

Violence is the most common problem of our contemporary world and, unfortunately, it has become an ordinary, common thing, people coexisting with this phenomenon without minding the danger it represents for everyday life. The media constantly reports on extreme cases of violence, such as wars, crimes, stealing, fighting, destruction of goods and, of course, verbal violence, always present in all the social institutions and environments.

Due to the complexity of this concept and its different manifestation forms, violence is difficult to define, being often associated with and mistaken for aggression. Nevertheless, the specialists in the field manage to distinguish between the two terms.

Gradually, the term has gained a recent meaning, that of violent and destructive behaviour directed at objects, one's own person or other individuals. Therefore, there occurs the need to distinguish between the intention and the violent act in itself. When we use the term aggression, we mean intention. Nevertheless, it is no wonder that the two concepts, that of aggression and violence, often interconnect and support one another within definitions and causes, to help complete the research.

Not surprisingly, anger is correlated with disadvantages, for example, poverty, mental and physical impairment and marginalization. We may even notice the fact that anger, hostility and aggression cover generations, by means of yet insufficiently known mechanisms.

Violence is defined as the deliberate threat or use of physical force or power against oneself, somebody else or against a group or community, which entails or presents an enormous risk to entail a traumatism, death, psychological alteration, precarious development or privations (World report on violence and health, World Health Organization - Geneva, 2002).

The Council of Europe has launched, in 2002, a project on everyday violence, comprising modules on the various types of violence occurring in the contemporary society. Violence is present both in private and public life, as well as in institutions, among which school, as a public, institutionalized space, occupies a privileged position. 
The need to raise awareness, through social campaigns and educational programmes aimed at building a culture of non-violence and ameliorating the manifestation of violence in human relations is part of the work agenda of state institutions, NGOs and the media.

The manifestation of violence involves the following psychological and social factors: the feeling of injustice, lack or low level of empathy, pride and the devaluation of the individual, emotional immaturity, impulsiveness, lack of self-control, social distance, inferior versus superior, subordinate versus higher-up, the relation of power, relations of gender inequality, having the upper hand in a couple.

Violence is a reality characteristic of human nature, with continuity throughout human history. Violence has always existed and continues to manifest itself across the most diverse geographical spaces, cultural traditions and reigns. The animal, human and even vegetal reigns

are equally endowed with the ability to be aggressive, violent. The patterns for violence manifestation are distinct for each category. Despite its wide spread, the profile of violence wears the mark of the species, epoch, cultural and historic environment in which it is manifested, shaped by the strong fingerprint of individuals, the personality and psychic particularities of each person.

Therefore, aggression and violence are inherent characteristics of human nature, instincts impossible to eradicate. In fact, the attempt is to change the attitude towards violence, its gradual devaluation by raising awareness of its negative, undesirable consequences and increasing the control of violent, collective or individual impulses. At present, genocidal tendencies, coupled with technological progress and destruction of ecological resources, represent the highest risks for the human species. Thus, the future of our species looks uncertain. In order to understand genocide as a dramatic form of collective violence, we should resort to biology, ethics and psychology.

Man has aggressive tendencies, as revealed throughout history by the constant presence of violence and wars. From a social perspective, the approach to violence is more complex, because man is a social animal: the relations of power and domination, the need to subject and exploit, pride and intolerance, the inability to solve conflicts in a peaceful way are all characteristic of man.

\section{I.2. Approach}

The claim that school aggression and violence has reached, in recent decades, impressive levels, is turning into a common statement of the public discourse. A simple review of the known cases and types provides a dark image of this phenomenon. For example, we may watch on television, with surprise, how students aggress their mates or teachers while the whole event is being recorded on a mobile phone. All these, overlapping an excessively fast dynamics of the modern lifestyle, are able to build increased adjustment tensions and the deepening of the perceptions regarding deviant phenomena. 


\section{Empirical Research Concerning the Elimination of Violence in Mathematics Lessons}

All the factors involved in the aggressive school situation, students, parents, teachers, schools as institutions and the civil society are caught in this dynamics. Thus, in the school situation, the separate universes create different needs, false perceptions and attributions, and trigger aggression.

The two categories involved educationally, teachers and students, may become either aggressors or victims. Regarding students, the violent states may originate in factors such as behaviour models, lifestyle and life philosophy, frustrations accumulated throughout life and personal weaknesses. Regarding teachers, these materialize due to the degree of professionalism, personal vulnerability, inadequate pedagogical strategies, flawed pedagogical experience and, sometimes, depending on age or gender, the discipline which is being taught (those with secondary disciplines may feel less important and respected than those whose disciplines are regarded as fundamental).

\section{I.3. Explanatory models and theories}

When it comes to the teacher and his influence upon school situations, we refer to the ability to manage educational contexts as well as to give the educational relationship a positive or negative character. The educational style used by each teacher is also important for the students' training, in catching their attention and shaping their attitude towards school and education in general. Lack of flexibility, hardness, favouritism, injustice in giving marks, lack of communication, negligence, indifference and lack of involvement in the taught discipline build a situation unfavourable for the student, brings dissatisfaction, frustrations and victimization, generating a feeling of insecurity and lack of motivation. The psychological consequences of these manifestations are immediate and easily visible, affecting the students' level of school performance, emotional balance, social insertion and self-esteem.

On the other hand, the students themselves may participate in spreading the school violence, through negative physical and verbal attitudes, such as insults, humiliation, irony addressed to their classmates or teachers. Coming from very different backgrounds, with different intellectual and aggressive potentialities, the frustrations experienced at the school level are able to precipitate the development of aggressive behaviour among students. If the frustrations are related to the process of education in itself, the student refuses to accomplish the school tasks, misses school and behaves inadequately.

However, the most common negative school behaviours are yet, unfortunately, regarded as minor and designated by Americans through the term bullying, which means harassment. These actions include contempt, offence, disrespect, brutality, intimidation, peer bullying and create a tense classroom atmosphere, destroying group dynamics. Due to their discrete nature, these actions are often regarded as harmless, but they are related to the very dynamism of social relations, the social building and assertion of the child and the confidence the child has in the school environment and everyday life. 


\section{THE RESEARCH METHODOLOGY}

\section{II.1. The applicative research objectives}

The objectives of this research imply:

- Discovering the level and types of violence most often used in schools, especially when the teacher has inappropriate conduct towards the students.

- Building optimal conditions for the assertion of the individual potential of each student; organizing varied learning activities according to each student's development pace and level; stimulating intellectual efforts, collaboration, interest and motivation for applying Mathematics in varied contexts; adopting attractive and efficient teaching-learning-evaluation style and methods; approaching forms of organization characteristic of the psychological profile of each child and building the interest in and sensitivity towards new problems, as well as stimulating students to work in teams.

\section{II.2. The applicative research hypothesis}

A preventive type of approach to violence in school implies the identification and constant miniaturization of the teacher-student relationship. The applied research relied on the

\section{HYPOTHESIS:}

If we eliminate the possible sources of tension in the school environment, namely, verbal aggression, lack of transparency in evaluating students, discriminatory attitudes and marginalization of some of the students during class activities, unattractive organization of learning, lack of encouragement for students, encouragement of competition more than of cooperation, inducing feelings of failure, attitude of control instead of support for learning, then motivation for the learning activity as well as the school performance will be enhanced and the potential for aggression much diminished.

\section{II.3. The applicative research methodology}

The research was conducted by 20 students in the $3^{\text {rd }}$ year at the Faculty of Mathematics, "Vasile Alecsandri" University of Bacău, by assisting 24 lessons and holding 24 probation and final lessons of Mathematics, on a group of $968^{\text {th }}$-graders from "Octavian Voicu" Elementary School from Bacău, where the teaching practice was conducted.

The investigation among students was conducting by means of two questionnaires, which highlighted nuanced opinions. In the first questionnaire, we asked students to appreciate the frequency of the phenomena mentioned below, in their school. 
Table 1. Questionnaire on the misbehaviour of teachers

\begin{tabular}{|l|l|l|l|l|l|}
\hline & $\begin{array}{l}1 . \\
\text { Never }\end{array}$ & $\begin{array}{l}2 . \\
\text { Seldom }\end{array}$ & $\begin{array}{l}3 . \\
\text { Often }\end{array}$ & $\begin{array}{l}4 . \\
\text { Very } \\
\text { often }\end{array}$ & $\begin{array}{l}5 . \\
\text { I do not } \\
\text { know }\end{array}$ \\
\hline $\begin{array}{l}\text { 1. Did teachers punish you when } \\
\text { you did not know the lesson? }\end{array}$ & & & & & \\
\hline $\begin{array}{l}\text { 2. Do teachers humiliate you by } \\
\text { inappropriate words? }\end{array}$ & & & & & \\
\hline $\begin{array}{l}\text { 3. Do teachers resort to physical } \\
\text { punishment? }\end{array}$ & & & & & \\
\hline $\begin{array}{l}\text { 4. Are you penalized if you ask } \\
\text { teachers uncomfortable questions? }\end{array}$ & & & & \\
\hline $\begin{array}{l}\text { 5. Do teachers stimulate you more } \\
\text { to compete and less to collaborate? }\end{array}$ & & & & & \\
\hline $\begin{array}{l}\text { 6. Do teachers have enough } \\
\text { patience to listen to your } \\
\text { problems? }\end{array}$ & & & & & \\
\hline $\begin{array}{l}\text { 7. Do teachers allow you to } \\
\text { express original ideas? }\end{array}$ & & & & \\
\hline $\begin{array}{l}\text { 8. Do teachers discuss with you } \\
\text { outside classes? }\end{array}$ & & & & & \\
\hline $\begin{array}{l}\text { 9. Do teachers favour certain } \\
\text { students for no reason? }\end{array}$ & & & & & \\
\hline $\begin{array}{l}\text { 10. Is the lesson presentation } \\
\text { attractive for students? }\end{array}$ & & & & \\
\hline $\begin{array}{l}\text { 11. Do teachers behave in a cold } \\
\text { manner with you? }\end{array}$ & & & & \\
\hline 12. Other situations: & & & & \\
\hline
\end{tabular}

\section{II.4. The organization and statistical processing of the obtained data}

The proportion of students declaring that such teacher misbehaviour is manifested often is $4,25 \%$, the seldom frequency reaching the percentage of 20\%, (even 30\% for the statement Do you receive warning if you ask teachers uncomfortable questions?, and for Do teachers humiliate or use irony against you?, the percentage is quite high - 25\%) 
Table 2. The synthetic table of the obtained results

\begin{tabular}{|l|c|c|c|c|c|}
\hline \multicolumn{1}{|c|}{} & Often & Seldom & Never & $\begin{array}{l}\text { I do not } \\
\text { know }\end{array}$ & \\
\hline $\begin{array}{l}\text { Do teachers resort to physical } \\
\text { punishment? }\end{array}$ & 2 & 20 & 60 & 10 & 8 \\
\hline $\begin{array}{l}\text { Do teachers humiliate or use irony } \\
\text { against you? }\end{array}$ & 5 & 20 & 55 & 12 & 8 \\
\hline $\begin{array}{l}\text { Do you receive warning if you ask } \\
\text { uncomfortable questions? }\end{array}$ & 5 & 25 & 60 & 5 & 5 \\
\hline $\begin{array}{l}\text { Are you punished when you do not } \\
\text { know the lesson? }\end{array}$ & 5 & 15 & 60 & 15 & 5 \\
\hline Achievement rate & $4,25 \%$ & $20 \%$ & $58 \%$ & $10,5 \%$ & $6,75 \%$ \\
\hline
\end{tabular}

\section{II.5. Psycho-pedagogical analysis and interpretation of the results obtained}

Figure 1 Psycho-pedagogical analysis of the results obtained

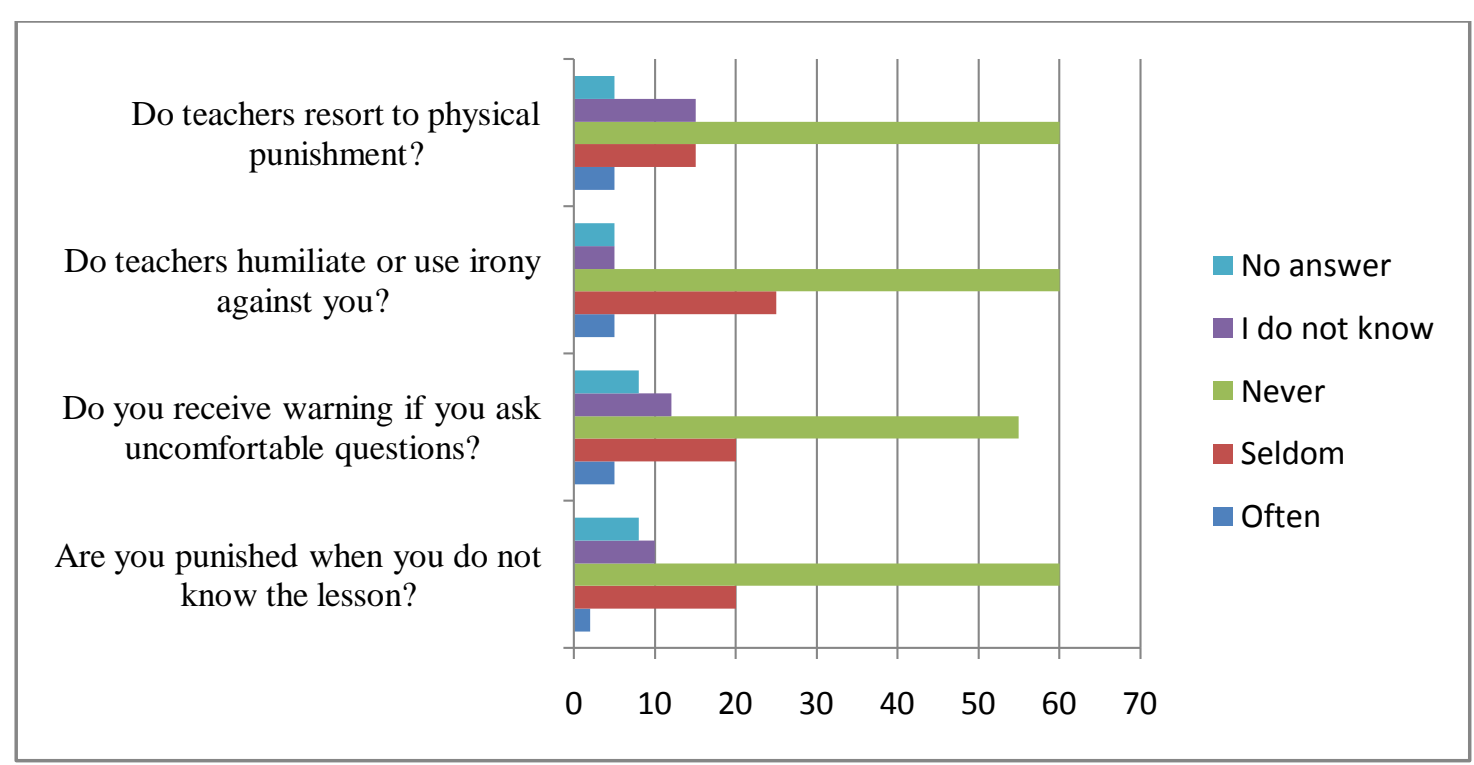


Therefore, the obtained results indicate the prevalence of verbal violence in the teacher-student relationship, the children feeling uncomfortable, threatened by the teachers' behaviour, thus occurring the feeling of discouragement and even refusal to participate in classes and collaborate with the school environment.

To evaluate the potential of aggression, we have applied the test below, both at the beginning of the teaching practice, 01.10.2014, and at the end of the teaching practice, 20.12.2014. The test required the expression of agreement or disagreement on a scale from 1 to 5 , for each item.

Table 3. Test for evaluating the aggression potential

\begin{tabular}{|c|c|c|c|c|c|}
\hline \multirow{2}{*}{$\begin{array}{l}\text { ITEMS: } \\
\text { 1. Do you feel directly concerned when someone criticizes } \\
\text { something? }\end{array}$} & \multirow[t]{2}{*}{ u } & \multirow[t]{2}{*}{ A } & \multirow[t]{2}{*}{$\omega$} & \multirow[t]{2}{*}{ N } & \multirow[t]{2}{*}{ 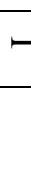 } \\
\hline & & & & & \\
\hline 2. Do you often bully others? & & & & & \\
\hline 3. Do you think you would be able to do harm to a colleague? & & & & & \\
\hline 4. Are you often told that you are impulsive? & & & & & \\
\hline 5. Do you usually get into fights? & & & & & \\
\hline 6. In a conflict, do you give in only with great difficulty? & & & & & \\
\hline $\begin{array}{l}\text { 7. Do you believe you are a good leader and that others must } \\
\text { obey you? }\end{array}$ & & & & & \\
\hline $\begin{array}{l}\text { 8. Do your preferences have primacy over the preferences of } \\
\text { others in all circumstances? }\end{array}$ & & & & & \\
\hline 9. Do you like violent actions? & & & & & \\
\hline 10. Are you always silent, angry and fierce? & & & & & \\
\hline 11. Do you get back at your mates for previous offenses? & & & & & \\
\hline 12. Do you feel satisfied when you see the others defeated? & & & & & \\
\hline 13. Are you easily annoyed? & & & & & \\
\hline $\begin{array}{l}\text { 14. Do you prefer to be categorical, even if this means to } \\
\text { trample on others? }\end{array}$ & & & & & \\
\hline 15. Do enemies exist only to make your life more interesting? & & & & & \\
\hline 16. Do you raise your voice easily in a discussion? & & & & & \\
\hline 17. Are you easily irritated and ready to retaliate? & & & & & \\
\hline $\begin{array}{l}\text { 18. Are you a fan of a sports team defending its honour in } \\
\text { every situation? }\end{array}$ & & & & & \\
\hline 19. When you are criticized, do you respond sharply? & & & & & \\
\hline $\begin{array}{l}\text { 20. Do you usually tell your opinion openly, although this may } \\
\text { offend others? }\end{array}$ & & & & & \\
\hline $\begin{array}{l}\text { 21. Do you pay little attention to conveniences and prefer to } \\
\text { go straight to the point? }\end{array}$ & & & & & \\
\hline 22. Is it obvious that in life nothing can be achieved without a & & & & & \\
\hline
\end{tabular}




\begin{tabular}{|l|l|l|l|l|l|}
\hline fight? & & & & & \\
\hline 23. Do you generally regard yourself as a redeemer? & & & & & \\
\hline $\begin{array}{l}\text { 24. During arguments, are you inclined to push the } \\
\text { conversation to the hilt? }\end{array}$ & & & & \\
\hline 25. Are you sometimes afraid of your own aggression? & & & & \\
\hline Total: & & \\
\hline
\end{tabular}

Anger is the reason for the highest availability of aggressive action, being associated with increased physiological excitement, which determines the intensity of the inner mood and its behavioural expression. The causes of anger vary, the most often causes being the threat to one's state of wellness or frustrations. The main anger-inducing cause is the perception of injustice in relation to one's own person or others, anticipating the intention to punish the individual who has violated a moral rule.

After answering all items, the points obtained were gathered and the scores interpreted according to the grid below:

Table 4 Scores interpreted according to the grid

\begin{tabular}{|c|c|c|c|}
\hline 25-50 POINTS & 51-75 POINTS & 76-100 POINTS & 101-125 POINTS \\
\hline $\begin{array}{l}\text { You are a rather } \\
\text { peaceful person. You } \\
\text { are characterized by the } \\
\text { utmost calm, avoiding } \\
\text { all forms of violence or } \\
\text { use of force. You give } \\
\text { in easily, even when } \\
\text { things are obviously to } \\
\text { your disadvantage. }\end{array}$ & $\begin{array}{l}\text { Sometimes you } \\
\text { react violently, but } \\
\text { seldom by verbal } \\
\text { means. You like to } \\
\text { be left alone. You } \\
\text { have self-control, } \\
\text { your aggressive } \\
\text { reactions are quite } \\
\text { rational. }\end{array}$ & $\begin{array}{lr}\text { Generally, you } \\
\text { manage to control } \\
\text { your aggression, } \\
\text { although r } \\
\text { sometimes you } \\
\text { haver violent } \\
\text { outbursts. You } \\
\text { should control the } \\
\text { manifestation of } \\
\text { your negative } \\
\text { states better. }\end{array}$ & $\begin{array}{l}\text { You have difficulties } \\
\text { in controlling your } \\
\text { tendency towards } \\
\text { aggression. You } \\
\text { solve all situations } \\
\text { by aggressive } \\
\text { means. You are } \\
\text { difficult to work } \\
\text { with, therefore you } \\
\text { should work on } \\
\text { building self-control. }\end{array}$ \\
\hline
\end{tabular}

School failure is a relevant risk factor when it comes to school violence. The internalized feeling of failure entails deep and lasting psychological marks, often expressed through violent behaviour. 


\section{II.6. Comparative data analysis and progress record}

Analysing the results to the test for evaluating the aggression potential, we may notice, as shown in the graph below, the progress/ regress of scores from one test to the other one. If in the initial test there were recorded $29 \%$ students with proper behaviour and attitude, their number increased in the final test to $42 \%$. A relevant decrease also occurred between the initial and final test at those with high aggression potential, from $19 \%$ to $8 \%$.

Comparing the results obtained by the students to the initial and final tests for evaluating the aggression potential, we may find a relevant progress of skills in communication, calculus and correct use of mathematical concepts.

Enhancing the number of students who obtained Good and Very good results is remarkable, having led to diminishing the frustrations related to the educational process, the students accepting to accomplish school tasks without missing classes and displaying an appropriate behavior. The results are shown in the table and diagram below.

Table 5 Table with the results to the test for evaluating the aggression potential

\begin{tabular}{|c|c|c|c|c|}
\hline & 25-50 points & 51-75 points & $76-100$ points & $101-125$ points \\
\hline Initial test & 28 & 26 & 24 & 18 \\
\hline Final test & 40 & 34 & 14 & 8 \\
\hline
\end{tabular}

ram with the results to the test for evaluating the aggression potential

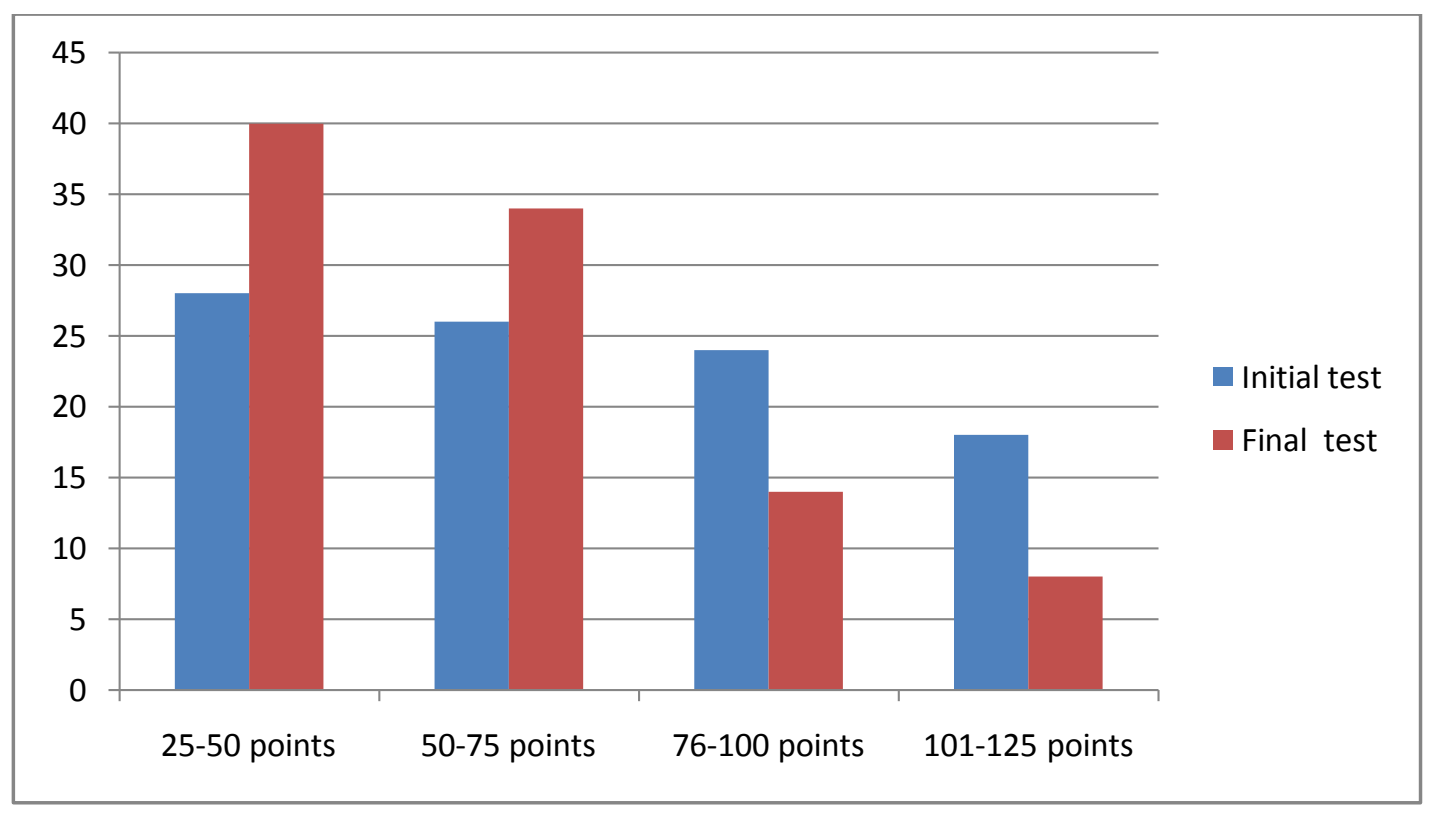

Thus, the progress factor applied to the actual activity of solving problems and exercises of Mathematics has considerably contributed to building efficient skills of intellectual work and 
improving school performances at Mathematics. Individualized activity considers the work pace, skills, physical and intellectual endurance of each child, recording the progress of each student based on his own activity. Differentiation and the teaching-learning style is the key to full success in school teaching and learning. By applying the differentiation of training students, we support the identification of cognitive interests, special skills, providing proper circumstances to build them, so that each student may experience the feeling of success.

In order to shape human nature, education should always rely on knowledge of the structure and dynamics of personality features, the level of intellectual, emotional and attitudinal development.

During the teaching practice, the university students created optimal conditions for asserting the individuality potential of each child in personalized contexts. They organized diverse learning activities according to the children's development pace and level, stimulated intellectual efforts, collaboration, interest and motivation for applying Mathematics in varied contexts. They adopted teaching-learning-evaluation methods for each content and form of organization, as well as for the psychological profile of each child, developed interest and sensitivity for new problems, stimulating students to work in teams.

\section{CONCLUSIONS}

The results obtained by students in their final evaluation confirm the research hypothesis. These acquisitions materialize in enhancing the students' motivation for the learning activity, raising school performance, filling in knowledge gaps and achieving established objectives.

The students have shown initiative in transposing various situations into Mathematical contexts, they have overcome blockages in solving problems, displayed proper behaviour towards their group mates. Since students are different in terms of skills, learning pace, degree of understanding phenomena, ability to learn and results obtained, there was achieved an individual and differentiated treatment of the students by means of modern, active methods and procedures, individualized actions conducted on the background of frontal activities, activities in groups of different levels, with the assignment of different tasks.

The results obtained at evaluations and the positive feedback have motivated students, confirming the work hypothesis. Differentiated activity has high practical value, as it prevents the dragging of students with difficulties in assimilating knowledge, stimulating students with special skills, enhancing the efficiency of the instructive-educational process.

Educational institutions are a training and learning place where relationships are established, models and values are promoted, conditions are created for the child's cognitive, emotional and moral development. Teachers should pay greater attention to the teaching strategies and how they address students, use efficient methods of interaction and relationing at the disciplines they 
teach, in order to ensure appropriate functioning of the teacher-student relationship and psychologically protect children.

\section{REFERENCES}

1. Barna I., Barna O., (2014), The effectiveness of school-based violence prevention programs for reducing aggressive behavior, Procedia - Social and Behavioral Sciences, no. 137 , p. $88-92$.

2. Gavidia V., Talavera M., Hamdan J., Violence at school: a sample of young Muslims and young Valencians, Procedia - Social and Behavioral Sciences, no. 132, ( 2014 ), p. 596 602.

3. Jigău M., Bălica M., Fartusnic C., Liiceanu, A., Marutescu A., , Săucan D., Voinea D., Preventing and Combating Violence in School: Practical Guide for Executives and Teachers, Buzau, Publisher Alpha, 2011.

4. Lupu C., Research on the Individual Development of Children by Eliminating Stressors, The International Journal of Indian Psychology, Volume 2, Issue 1, 2014, p.102-114.

5. Marian C., Aggression in school: Determinations, mechanisms and trajectories, ClujNapoca, Publisher Limes, 2011.

6. Sălăvăstru D., Psychology of Education, Iași, Publisher Polirom, 2004.

7. Violence in School, Institute of Education Sciences UNICEF, Bucharest, Publisher Alpha MDN, 2006. 